\title{
EDITORIAL
}

\section{How can we improve the management and outcome of pneumonia in the elderly?}

\author{
V. Brito* and M.S. Niederman*,\#,
}

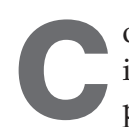

ommunity-acquired pneumonia (CAP) is a common illness, with increased mortality in certain populations, particularly the elderly and those with severe illness [1-3]. The association between advanced age and mortality is well known; Sir William Osler's infamous view was that pneumonia was the "friend of the aged" that often allowed patients with advanced illness to die peacefully. In spite of this viewpoint, it remains uncertain whether ageing itself adds to this mortality risk or whether the adverse outcomes of CAP in the elderly are the consequence of other factors, some of which might be modified, such as the presence of comorbid illnesses and the therapies required to manage them, or the delays in the diagnosis of pneumonia that result from indistinct clinical presentations in the elderly.

FRY et al. [1] studied the data of the National Hospital Discharge Survey and found that in older hospitalised patients with pneumonia, at least one underlying medical condition was reported in most medical records. MARSTON et al. [2] studied hospitalised patients with CAP for $1 \mathrm{yr}$ in two counties in Ohio, USA. Amongst the 2,776 patients studied, the incidence and mortality of pneumonia in the elderly was much higher than in younger populations. KAPLAN et al. [3] reported the 1-yr mortality of elderly patients admitted for CAP and observed that beyond the immediate $12 \%$ in-patient mortality rate, there was a 1-yr death rate of $>40 \%$, raising the question as to whether pneumonia is a surrogate marker of other types of serious illness in the elderly.

Numerous factors could contribute to the high mortality rate of CAP in the elderly. It is more difficult to diagnose pneumonia in the elderly than in young patients because the usual clinical clues for its diagnosis might be absent at the time of onset of illness. Riquelme et al. [4] found that the cardinal signs and symptoms, such as cough, fever and dyspnoea, may not be present in some older patients with pneumonia. MeTLAY et al. [5] studied 1,812 pneumonia patients and observed that both respiratory and nonrespiratory symptoms were less commonly reported by older patients than by younger patients, even after controlling for the increased frequency of comorbidity and

*Division of Pulmonary and Critical Care Medicine, ${ }^{\#}$ Dept of Medicine, Winthrop University Hospital, Mineola, and "Dept of Medicine, Stony Brook Campus, State University of New York, NY,

STATEMENT OF INTEREST: A statement of interest for M.S. Niederman can be found at www.erj.ersjournals.com/misc/statements.shtml

CORRESPONDENCE: M.S. Niederman, Winthrop University Hospital, 222 Station Plaza N, Suite 509, Mineola, NY 11501, USA. Fax: 1 5166638796. E-mail: mniederman@winthrop.org disease severity in elderly individuals. In a study by WATERER et al. [6] it was reported that the time to administration of the first dose of antibiotics for CAP was longer in the absence of fever and hypoxaemia, and in the presence of altered mental status and advanced age (implying a delay in disease recognition). It is probable that these delays in diagnosis and therapy contribute to the high mortality rate of CAP in older patients.

Other ways in which advanced age could indirectly increase CAP mortality include a high frequency of comorbid illness, as well as a predisposition to more virulent pathogens and pathogenic mechanisms. Pneumonia can also lead to worsening of chronic medical illnesses, such as chronic obstructive pulmonary disease and chronic heart disease. The coexistence of neurological and gastro-intestinal diseases in the elderly may account for their increased risk of aspiration as a common mechanism of infection. A different pattern of bacterial colonisation of the oropharynx is also seen in patients living in nursing homes, especially those with poor functional status, who are susceptible to harbouring Gram-negative bacteria and resistant strains of pneumococcus [7-9]. Immune dysfunction is common in the elderly, either as a consequence of comorbid illness or directly due to ageing itself $[10,11]$. Advanced age has been associated with changes in T-cell function, alterations in cell-mediated immunity, reductions in immunoglobulin production, a loss of high-affinity blocking antibodies and an increase in self-reactive antibodies. Nutritional impairment, such as low serum albumin levels in the elderly, is also associated with a higher risk of pneumonia [4].

In the current issue of the European Respiratory Journal, the study by Котне et al. [12] carefully examines the role of ageing as a cause of increased CAP mortality. Using a large German database from the Community-acquired Pneumonia Competence Network (CAPNETZ) study, the investigators found that age itself was a risk factor for mortality. A total of 1,298 patients $<65$ yrs of age and 1,349 patients $>65$ yrs of age were evaluated. In a multivariate analysis, the risk factors for 30-day mortality were found to be comorbid illness (congestive heart failure, cerebrovascular disease and chronic liver disease), residence in a nursing home, CURB score (a measure of disease severity according to: confusion; urea $>7 \mathrm{mM} \cdot \mathrm{L}^{-1}$; respiratory rate $\geqslant 30$ breaths $\cdot \mathrm{min}^{-1}$; blood pressure $<90 \mathrm{mmHg}$ systolic of $\leqslant 60 \mathrm{mmHg}$ diastolic; $\geqslant 65 \mathrm{yrs}$ of age), ineffective therapy, and age itself, with the risk rising for those $>65$ yrs of age. Amongst the elderly population, residence in a nursing home (healthcare-associated pneumonia) was associated with a greater mortality risk than residence at 
home, as were comorbid illness, higher CURB score and use of ineffective therapy. When elderly patients were compared to younger patients, they had more comorbid illness, lower body temperature, less pleuritic chest pain, more confusion, and higher blood urea nitrogen. Interestingly, the findings give many reasons as to why mortality was higher in older patients, including more frequent comorbid illness, less distinct presenting clinical signs and ineffective therapy but in addition, age itself was an independent risk factor. The only mortality risks that are under the control of the physician managing the patient are timely recognition of illness and administration of effective empirical therapy. Initial therapy is driven by a knowledge of likely aetiological pathogens, and in the study by KOTHE et al. [12], older patients generally had the same distribution of pathogens as younger patients, with pneumococcus dominating and the only difference being a lower frequency of Mycoplasma pneumoniae. Although the frequency of Gram negatives was not significantly higher in the elderly, these organisms were more common in those residing in a nursing home/chronic care facility than in those residing in the community in a home setting (18.8 versus $5.5 \%$ ).

All of these findings offer clues regarding how the mortality of pneumonia in older patients can be reduced. It is clear that there are subsets of the elderly with pneumonia, that those residing in the community are not the major source of mortality and that the bacteriology of elderly patients is similar to younger patients. Therefore, it is likely that these patients need a traditional CAP therapy regimen. The most important way to reduce their mortality risk is to recognise that with a high frequency of comorbid illness, such patients frequently receive delayed therapy due to indistinct clinical presentations. Thus, a high index of suspicion for pneumonia is required in this population. For those who reside in nursing homes, ineffective therapy can be avoided by considering their unique bacteriology and their risk for Gram-negative bacilli. Such patients are now categorised as having healthcareassociated pneumonia (HCAP), which was considered a form of nosocomial pneumonia in the 2005 American Thoracic Society/Infectious Diseases Society of America guidelines [13]. Also included in the HCAP population are those who have been in hospital in the past 90 days, those on haemodialysis and those receiving home wound care. The recommended empirical therapy for HCAP patients focused on multidrugresistant (MDR) pathogens, including drug-resistant pneumococcus, methicillin-resistant Staphylococcus aureus (MRSA) and Pseudomonas aeruginosa, using multiple broad-spectrum antimicrobial agents.

Several recent studies have examined HCAP, and the frequency of MRSA and enteric Gram negatives has varied widely [14, 15]. CARRATALÀ et al. [14] prospectively studied 126 HCAP patients (25.4\% were from nursing homes) and 601 CAP patients. Although their study found a higher frequency of inappropriate initial antibiotic therapy and a higher casefatality rate in patients with HCAP than CAP, Gram negatives and $S$. aureus were uncommon in HCAP patients ( 4 and $2.4 \%$, respectively). In contrast, MiCEK et al. [15] studied 431 HCAP patients retrospectively $(93 \%$ were hospitalised in the past 6 months, $28 \%$ were from nursing homes) and found S. aureus to be present in $24.6 \%$, pneumococcus in $20.3 \%$, $P$. aeruginosa in
$18.8 \%$ and MRSA in $13.8 \%$. Based on these findings, it is not surprising that use of a CAP regimen led to inappropriate therapy $30.9 \%$ of the time and inappropriate therapy was a risk factor for mortality. These two studies, combined with the data from the study by КОтНE et al. [12], which show a greater similarity bacteriologically to the study by CARRATALÀ et al. [14] than to the study by MiCEK et al. [15], make it clear that the HCAP population (including those in nursing homes) is very heterogeneous, and it is likely that appropriate therapy will need to vary according to patient features, recognising the presence of distinct patient subpopulations.

Other studies have helped us understand the clinical associations of MDR pathogens in CAP. ARANCIBIA et al. [16] identified the risk factors for Gram-negative pneumonia to be: previous hospital admission; history of antibiotic use in the 30 days prior to pneumonia; the presence of a pulmonary comorbidity; and possible aspiration. EL SOLH et al. [17] found that in those with severe pneumonia residing in a nursing home/chronic care facility, the risk factors for infection with MDR pathogens were prior antibiotic therapy in the past 6 months and the presence of poor functional status.

The data from all of these studies make it clear that not all healthcare-associated pneumonia patients are at risk for infection with multidrug-resistant pathogens, and thus, that not all of these patients require a multidrug, broad-spectrum regimen. In fact, monotherapies such as levofloxacin [18], cefepime and ertapenem [19] have been effective for some patients with pneumonia residing in a nursing home/chronic care facility. Based on current understanding, we suggest that for the elderly patient with pneumonia, there is not only a need for appropriate therapy but also for therapy that is not broader spectrum than necessary. Thus, unlike the recommendations in the nosocomial pneumonia guidelines of the American Thoracic Society/Infectious Diseases Society of America, broad-spectrum, multidrug regimens should be reserved only for healthcare-associated pneumonia patients who have at least two of the following: severe illness, poor functional status and prior antibiotic therapy [20]. Those with healthcareassociated pneumonia, and other elderly patients, could be treated more like traditional community-acquired pneumonia patients in the absence of these risk factors. In the future, it is hoped that we will understand these subpopulations better and realise that there is not just one simple approach to therapy, but rather a need for individualised therapy, based on individual patient factors [20].

\section{REFERENCES}

1 Fry AM, Shay DK, Holman RC, Curns AT, Anderson LJ. Trends in hospitalizations for pneumonia among persons aged 65 years or older in the United States, 1988-2002. JAMA 2005; 294: 2712-2719.

2 Marston BJ, Plouffe JF, File TM Jr, et al. Incidence of community-acquired pneumonia requiring hospitalization. Results of a population-based active surveillance study in Ohio. The Community-Based Pneumonia Incidence Study Group. Arch Intern Med 1997; 157: 1709-1718.

3 Kaplan V, Clermont G, Griffin MF, et al. Pneumonia: still the old man's friend? Arch Intern Med 2003; 163: 317-323. 
4 Riquelme $\mathrm{R}$, Torres A, el-Ebiary $\mathrm{M}$, et al. Communityacquired pneumonia in the elderly. Clinical and nutritional aspects. Am J Respir Crit Care Med 1997; 156: 1908-1914.

5 Metlay JP, Schulz R, Li YH, et al. Influence of age on symptoms at presentation in patients with communityacquired pneumonia. Arch Intern Med 1997; 157: 1453-1459.

6 Waterer GW, Kessler LA, Wunderink RG. Delayed administration of antibiotics and atypical presentation in community-acquired pneumonia. Chest 2006; 130: 11-15.

7 El-Sholh AA, Pietrantoni C, Bhat A, et al. Colonization of dental plaques: a reservoir of respiratory pathogens for hospital-acquired pneumonia in institutionalized elders. Chest 2004; 126: 1575-1582.

8 Niederman MS. Pathogenesis of airway colonization: lessons learned from studies of bacterial adherence. Eur Respir J 1994; 8: 1737-1740.

9 Valenti WM, Trudell RG, Bentlye DW. Factors predisposing to oropharygeal colonization with gram negative bacilli in the aged. N Engl J Med 1978; 298: 1108-1111.

10 Donowitz GR, Cox HL. Bacterial community-acquired pneumonia in older patients. Clin Geriatr Med 2007; 23: 515-534.

11 Janssens JP, Krause KH. Pneumonia in the very old. Lancet Infect Dis 2004; 4: 112-124.

12 Kothe H, Bauer T, Marre R, et al. Outcome of communityacquired pneumonia: influence of age, residence status and antimicrobial treatment. Eur Respir J 2008; 32: 139-146.

13 American Thoracic Society/Infectious Diseases Society of America. Guidelines for the management of adults with hospital-acquired, ventilator-associated, and health careassociated pneumonia. Am J Respir Crit Care Med 2005; 171: 388-416.

14 Carratalà J, Mykietiuk A, Fernández-Sabé N, et al. Health care-associated pneumonia requiring hospital admission: epidemiology, antibiotic therapy, and clinical outcomes. Arch Intern Med 2007; 167: 1393-1399.

15 Micek ST, Kollef KE, Reichley RM, et al. Health careassociated pneumonia and community-acquired pneumonia: a single-center experience. Antimicrob Agents Chemother 2007; 51: 3568-3573.

16 Arancibia F, Bauer TT, Ewig S, et al. Community-acquired pneumonia due to gram-negative bacteria and Pseudomonas aeruginosa: incidence, risk and prognosis. Arch Intern Med 2002; 162: 1849-1858.

17 El Solh AA, Pietrantoni C, Bhat A, et al. Indicators of potentially drug-resistant bacteria in severe nursing homeacquired pneumonia. Clin Infect Dis 2004; 39: 474-480.

18 Loeb M, Carusone SC, Goeree R, et al. Effect of a clinical pathway to reduce hospitalizations in nursing home residents with pneumonia: a randomized controlled study. JAMA 2006; 295: 2503-2510.

19 Yakovlev SV, Stratchounski LS, Woods GL. Ertapenem versus cefepime for initial empirical treatment of pneumonia acquired in skilled-care facilities or in hospitals outside the intensive care unit. Eur J Clin Microbiol Infect Dis 2006; 25: 633-641.

20 Niederman MS, Brito V. Pneumonia in the older patient. Clin Chest Med 2007; 28: 751-771. 